\title{
Site disparities in apoptotic variants as predictors of risk for second primary malignancy in patients with squamous cell carcinoma of the head and neck
}

Yan Sun ${ }^{1,2+}$, Wenbin $\mathrm{Yu}^{1,3+}$, Erich M. Sturgis ${ }^{1,4}$, Wei Peng ${ }^{5}$, Dapeng Lei ${ }^{1,6}$, Qingyi Wei ${ }^{7}$, Xicheng Song ${ }^{1,2^{*}}$ and Guojun $\mathrm{Li}^{1,4^{*}}$

\begin{abstract}
Background: FAS/FASL promoter variants are considered in altering transcriptional activity of those genes and consequently alter regulation of cell death. However, no studies have investigated whether tumor sites contribute to the association between FAS/FASL polymorphisms and risk for second primary malignancy (SPM).

Method: In this study, FAS670 A > G, FAS1377 G > A, FASL124 A > G, and FASL844C > T polymorphisms were genotyped in 752 OPC and 777 non-OPC patients. Both univariate and multivariable cox proportional hazard models were used to assess the associations.

Results: The univariate and multivariable analyses showed that patients with index OPC and FASL844 CT/TT genotype had significantly increased risk of SPM (cHR, 2.5; $95 \% \mathrm{Cl}, 1.1-5.8, P=0.043$ and aHR, $2.7 ; 95 \% \mathrm{Cl}, 1.2-6.0, P=0.032)$ compared with those with FASL844 CC genotype as the reference group, while index non-OPC patients with FAS670 AG/GG and FasL844 CT/TT genotypes had significantly increased risk of SPM (CHR, 2.2 and 1.8; $95 \%$ Cl, 1.2-5.7 and 1.1-3.2; and $P=0.04$ and 0.041, respectively and $\mathrm{aHR}, 2.4$ and $1.7 ; 95 \% \mathrm{Cl}, 1.1-5.1$ and 1.0-3.0; and $P=0.043$ and 0.049 , respectively) compared with their corresponding AA and CC genotypes. Moreover, patients carrying more FAS/FASL variants significantly increased risk of SPM among index non-OPC patients. The stratified analysis showed that smoking status differently modified the associations between FAS/FASL polymorphisms and risk of SPM among index non-OPC from OPC patients.
\end{abstract}

Conclusion: These results suggested that FAS/FASL polymorphisms might significantly modify SPM risk among patients with SCCHN in a tumor site-specific manner.

Keywords: FAS/FASLG, Squamous cell carcinoma of head and neck, Second primary malignancy, Susceptibility, Polymorphism, Oropharyngeal cancer, Nonoropharyngeal cancer

\footnotetext{
*Correspondence: Songxicheng@126.com; gli@mdanderson.org

${ }^{\dagger}$ Equal contributors

${ }^{1}$ Department of Head and Neck Surgery, Unit 1445, The University of Texas

MD Anderson Cancer Center, 1515 Holcombe Boulevard, Houston TX 77030,

USA

Full list of author information is available at the end of the article
}

\section{Ciomed Central}

C 2016 Sun et al. Open Access This article is distributed under the terms of the Creative Commons Attribution 4.0 International License (http://creativecommons.org/licenses/by/4.0/), which permits unrestricted use, distribution, and reproduction in any medium, provided you give appropriate credit to the original author(s) and the source, provide a link to the Creative Commons license, and indicate if changes were made. The Creative Commons Public Domain Dedication waiver (http://creativecommons.org/publicdomain/zero/1.0/) applies to the data made available in this article, unless otherwise stated. 


\section{Background}

The squamous cell carcinomas of the head and neck $(\mathrm{SCCHN})$ arise in the upper aerodigestive tract including the oral cavity, the oropharynx, the hypopharynx, and the larynx [1]. The SCCHN are associated with a high incidence rate of second primary malignancy (SPM), for which the risk remains at a substantially high during the lifespan of the patients [2-5]. Although we have seen the declining trend of overall SCCHN incidence, the decrease in incidence of SPM is heterogeneous across all tumor sites within the head and neck regions.

The oropharyngeal cancer (OPC) has the features of an aggressive local tumor, with a moderately high recurrence rate, high frequency of SPM, and high frequency of medical comorbidities [6]. While the incidence of $\mathrm{OPC}$ is increasing, the attributable risk to SPM in patients with index OPC has declined since the 1990s. Moreover, the incidence of HPV-positive OPC cases increases among OPC patients, whereas the oropharynx is the subsite with the lowest SPM risk [3, 7-9]. Therefore, HPV is highly relevant to the SPM rates in OPC patients. The nonoropharyngeal cancer (non-OPC) includes tumors which occur in oral cavity, larynx, and hypopharynx. Compared with patients with OPC, the patients with non-OPC have the consistently high risk of SPM [3].

The SPMs in OPC and non-OPC patients still remain one of major factors that contribute to the poor prognosis of these patients [2, 10-12]. Cigarette smoking and alcohol use have been found to be associated with the risk of SPM [13, 14], while only a small proportion of these patients develop a SPM, suggesting that there is a person to person variation in genetic susceptibility to SPM among the patients [2]. We have previously reported that genetic polymorphisms involved in several molecular pathways were associated with the risk of SPM after primary SCCHN, such as carcinogen metabolism, DNA repair, and cell cycle control [12, 15-21].

Apoptosis is the physiological mechanism of programmed cell death that plays an important role in diverse biological processes such as development, homeostasis of tissues, and elimination of cancer cells [22, 23]. The acquired ability to resist apoptotic stimuli is one of the primary characteristics of a malignant cell, and abnormal regulation of apoptosis is a key mechanism in the development of cancer [24]. FAS is a cell surface receptor that can interact with FASLG to trigger apoptosis [25]. Therefore, FAS/FASLG pathway plays an important role in regulation of apoptosis and maintenance of cellular homeostasis, and genetic alteration of FAS/FASLG signaling pathway may result in immune escape, and thus tumorigenesis including SPM.

The two polymorphisms identified in the $F A S$ promoter region: FAS1377 G>A rs2234767 and FAS670 A > G rs1800682 result in decreased promoter activity and decreased FAS gene expression in consequence [26]. Another two polymorphisms in FASL promoter: FASL844 $\mathrm{C}>\mathrm{T}$ rs763110 and FASL 124. A > G rs5030772 may increase basal expression of $F A S L$, resulting in aberrant FASL expression and subsequently increased susceptibility to cancer $[26,27]$.

Although we have previously reported a study on association of these functional polymorphisms with SPM risk among SCCHN patients, showing that FAS670 and FASL844 polymorphisms were associated with a significantly increased risk for SPM in overall SCCHN patients [28], no studies have evaluated the associations between these polymorphisms with risk of SPM in different tumor sites of SCCHN. Since FAS/FASL pathway plays a critical role in apoptosis, this study might provide novel information for prognosis and secondary as well as tertiary cancer prevention of these patients. Therefore, we evaluated the associations between each or in combination of the four FAS/FASL genetic variants and risk of SPM among 752 index OPC and 777 index non-OPC patients, respectively.

\section{Methods}

\section{Study subjects}

All the participants with incident cases were consecutively recruited between May 1995 and December 2010 through the Head and Neck Center at The University of Texas, M.D. Anderson Cancer Center. The inclusion criteria for cases were: (1) newly diagnosed, histopathologically confirmed squamous cell carcinomas of the oral cavity, oropharynx, hypopharynx, or larynx; (2) no history of treatment with either chemotherapy or radiation therapy treatment; and (3) patients with previous history of cancer excepting non-melanoma skin cancer, distant metastases at presentation, primary tumors of the nasopharynx or sinoasal tract, primary tumors outside the upper aerodigestive tract, cervical metastases of unknown origin, or histopathologic diagnoses other than squamous cell carcinoma were excluded. The study received approval from the institutional review boards of both MD Anderson and Kelsey-Seybold, and all study subjects signed an informed consent when approached for recruitment. All patients completed a standardized questionnaire including demographic, exposure information (including tobacco and alcohol), work history, and family history data, and donated a blood sample for genotyping data at the time of recruitment. Participants who were not able to provide their blood samples during the recruitment were excluded in the analysis.

Patients were monitored through their treatment and post-treatment course with regularly scheduled clinical and radiographic examinations. SPMs were distinguished 
from local recurrences based on modified criteria of Warren and Gates [29]. Second lesions with different histophathologic type and/or occurring $>5$ years following treatment for the primary tumor and/or clearly separated by normal epithelium based on clinical and radiographic assessment were considered SPM. The second lesion was classified as a local recurrence rather than a SPM if there was discrepancy or differing opinion about the origin of the tumor. Pulmonary lesions were considered SPM if they had a non-squamous histology or if they were isolated squamous lesions $>5$ years from initial SCCHN and felt to be SPM by the thoracic oncologist and thoracic surgeon. Medical record review for follow-up status of all patients was performed under supervision of the staff head and neck surgeon. Patients who had smoked $>100$ cigarettes in their lifetimes were categorized as "eversmokers," and others were "never-smokers." Similarly, subjects who had drunk alcoholic beverages at least once a week for $>1$ year previously were as "ever-drinkers," and others were "never-drinkers." Clinical data were obtained at initial presentation and through follow-up examinations and included overall stage at presentation of index tumor, site of index tumor, and treatment. Index cancer stages were then dichotomized into the early stage (clinical stage I and II) and late stage (III and IV). Types of treatment were categorized into three groups: surgery only, surgery and chemotherapy and/or radiotherapy, and chemotherapy and/or radiotherapy.

\section{Genotyping}

Genomic DNA was extracted from a leukocyte cell pellet for $F A S / F A S L$ genotyping, which was obtained from the buffy coat by the centrifugation of $1 \mathrm{~mL}$ of whole blood, using the Qiagen DNA Blood Mini Kit (Qiagen Inc.) in accordance with the manufacturer's instructions. The genotyping of the four SNPs was performed as previously described [26]. Moreover, there was $100 \%$ concordance when we randomly selected at least $10 \%$ of the random samples to retest for confirmation of the original findings.

\section{Statistical analysis}

The statistical analyses were performed by Intercooled Stata 13.0 (Stata Inc., College Station, TX). All tests were two-sided, and a P-value $<0.05$ was considered the cutoff for statistical significance. All statistical tests were processed in patients with index OPC and in patients with index non-OPC separately. SPM was considered as the primary endpoint of this study. The Student's $t$ tests were used to compare the mean age and follow-up time of the patients who developed a SPM and those who did not. The differences in ethnicity, sex, smoking and alcohol status, index tumor stage, treatment, and genotype distributions between the two groups were evaluated using the chi-squared test. Time-to-event was calculated from the date of diagnosis of the index cancer patients to the date of SPM occurrence. Patients who did not know to have an event at the date of last contact, or who died were censored. The associations between individual epidemiological risk factors, clinical characteristics including index tumor stage and treatment variables, and time to the occurrence of SPMs, were initially assessed using univariate Cox proportional hazards regression models. The data were consistent with the assumptions of the Cox proportional hazards regression model from the examination of Kaplan-Meier survival curves. In the univariate and multivariable analyses (adjusted by age, gender, ethnicity, smoking and drinking status, index cancer stage, and treatment), the associations were calculated using hazard ratios (HR) and their $95 \%$ confidence intervals (CI) for the development of the SPMs. For each polymorphism, the wild-type genotype was set as the reference group; the variant genotypes of each polymorphism were combined. In addition, for the combined analysis of the four polymorphisms, the patients with $0-2$ risk genotypes as the low-risk group were used as the reference group in comparison with the group with 3-4 variant genotypes as the highrisk group.

\section{Results}

\section{Study patients characteristics}

The study subjects were a cohort of 1529 patients, including 752 patients with index OPC and 777 patients with non-OPC. There were significant differences in the median age at diagnosis and follow-up time between index OPC patients and index non-OPC patients ( 54 years $v s .59$ years; $P=0.0011 ; 51.3$ months; 63.8 months; $P=0.00012$, respectively), and patients who developed SPMs were more likely to be index non-OPC $(P=0.001)$ when we compared the patients with and without SPM. Our data indicated that patients with index OPC had a lower rate of SPM compared to those with non-OPC (approximately $6 \%$ vs. $11 \%)$. Table 1 shows the demographics, risk factors, and clinical variables for the 752 patients with index OPC and 777 patients with non-OPC. For OPC patients, there were $710(94.4 \%)$ patients who did not develop SPM and 42 (5.6\%) patients who developed SPMs. The median age at diagnosis was 54 years (range, 28-84 years). In this patient cohort, we found age and smoking were significantly associated with SPM development $(P=0.004$ for age and $P=0.010$ for smoking), while we did not observe significant differences between patients with and without SPMs, regarding other characteristic variables. For the patients with index non-OPC, there were 695 (89.4\%) patients who did not develop SPMs and 82 (10.9\%) patients who developed SPMs. The median age at diagnose was 
Table 1 Distribution of demographic and risk factors in the patient cohorts with index OPC and non-OPC

\begin{tabular}{|c|c|c|c|c|c|c|c|}
\hline \multirow[t]{2}{*}{ Variables } & \multirow{2}{*}{$\begin{array}{l}\text { Total } \\
\text { No. }\end{array}$} & \multicolumn{3}{|c|}{$\mathrm{OPC}(N=752)$} & \multicolumn{3}{|c|}{ Non-OPC $(N=777)$} \\
\hline & & SPM (N) & $\%$ & $p^{*}$ & SPM (N) & $\%$ & $p^{*}$ \\
\hline Total patients & 1529 & 42 & 5.6 & & 82 & 10.6 & \\
\hline Age & & & & 0.004 & & & 0.024 \\
\hline$\leq$ Median (57 years) & 770 & 12 & 28.6 & & 33 & 40.2 & \\
\hline > Median (57 years) & 759 & 30 & 71.4 & & 49 & 59.8 & \\
\hline Sex & & & & 0.546 & & & 0.170 \\
\hline Male & 1186 & 35 & 83.3 & & 62 & 75.6 & \\
\hline Female & 343 & 7 & 16.7 & & 20 & 24.4 & \\
\hline Tobacco smoking & & & & 0.010 & & & 0.037 \\
\hline Ever & 1009 & 22 & 52.4 & & 69 & 84.1 & \\
\hline Never & 520 & 20 & 47.6 & & 13 & 15.9 & \\
\hline Alcohol drinking & & & & 0.813 & & & 0.005 \\
\hline Ever & 1099 & 30 & 71.4 & & 69 & 84.1 & \\
\hline Never & 430 & 12 & 28.6 & & 13 & 15.9 & \\
\hline Ethnicity & & & & 0.598 & & & 0.028 \\
\hline Non-Hispanic White & 1333 & 38 & 90.5 & & 60 & 73.2 & \\
\hline Other & 196 & 4 & 9.5 & & 22 & 26.8 & \\
\hline Index cancer stage & & & & 0.240 & & & 0.035 \\
\hline | or || & 386 & 5 & 11.9 & & 26 & 31.7 & \\
\hline III or IV & 1143 & 37 & 88.1 & & 56 & 68.3 & \\
\hline Treatment $^{a}$ & & & & 0.511 & & & 0.111 \\
\hline S only & 253 & 0 & 0.0 & & 19 & 23.2 & \\
\hline$S / C / X$ & 335 & 4 & 9.5 & & 30 & 36.6 & \\
\hline$X / C$ & 941 & 38 & 90.5 & & 33 & 40.2 & \\
\hline
\end{tabular}

${ }^{*} \mathrm{X} 2$ test for differences between patients with and without SPM

${ }^{\mathrm{a}} \mathrm{S}$, surgery, C, chemotherapy, and $\mathrm{X}$, radiation

59 years (range, 18-94 years). We found that the patients who developed SPMs were more likely to be older $(P=0.024)$, ever smokers $(P=0.037)$, ever alcohol user $(P=0.005)$, non-Hispanic white $(P=0.028)$, and late disease stage $(P=0.035)$. However, these patients had no significant differences in developing SPMs, regarding sex $(P=0.170)$ and treatment $(P=0.111)$.

\section{FAS/FASL polymorphisms and risk of SPM after index OPC and non-OPC}

Table 2 shows both univariate and multivariable analyses on SPM risk associated with FAS/FASL polymorphisms after index OPC and non-OPC. For multivariable analysis, the estimates of associations were adjusted by age, gender, ethnicity, smoking and drinking status, index cancer stage, and treatment. The patients with OPC and FASL844 CT/TT genotypes were found to significantly increase the risk of SPM compared with those with the corresponding CC genotype (cHR, 2.5, $95 \% \mathrm{CI}, 1.1-5.8$, $P=0.043$ and aHR, 2.7, $95 \% \mathrm{CI}, 1.2-6.0, P=0.032$, respectively); however, such a significant association was not observed for other polymorphisms. In contrast, the non-OPC patients carrying FAS670 AG/GG and FASL844 CT/TT variant genotypes had approximately 2.5 times (cHR, 2.2, $95 \% \mathrm{CI}, 1.2-5.7, P=0.048$ and aHR, 2.4, $95 \% \mathrm{CI}, 1.1-5.1, P=0.043$, respectively) and 2.0 times (cHR, 1.8, $95 \% \mathrm{CI}, 1.1-3.2, P=0.041$ and aHR, 1.7, $95 \% \mathrm{CI}, 1.0-3.0, P=0.049$, respectively) increased risk of SPMs compared with those with the corresponding AA or CC genotypes, respectively.

\section{Associations of the combined FAS/FASL variant genotypes} with risk of SPMs after index OPC and non-OPC

As shown in Table 3, we performed the combined analysis of all 4 SNPs to focus on potentially modifying effect of the combined variant genotypes on risk of SPM since any of the 4NPs of FAS and FASL genes in the apoptotic pathway appeared to have a minor effect on risk of SPM. To perform the combined analysis of all 4 SNPs, we categorized all patients into 4 groups: (1) $0-1$ variant genotype group; (2) 2 variant genotype group; (3) 3 variant genotype group; and (4) 4 variant genotype 
Table 2 Genotype distribution of the FAS and FASL polymorphisms among patients with index OPC and non-OPC and their associations with risk of SPM

\begin{tabular}{|c|c|c|c|c|c|c|c|c|}
\hline \multirow[t]{2}{*}{ Variables } & \multicolumn{2}{|c|}{$\mathrm{OPC}(N=42)$} & \multicolumn{2}{|c|}{ Non-OPC $(N=82)$} & \multicolumn{2}{|l|}{$\mathrm{CHRs}^{\mathrm{a}}(95 \% \mathrm{Cl}), \mathrm{P}$} & \multicolumn{2}{|c|}{ Adj. HRs $(95 \% \mathrm{Cl})^{\mathrm{b}}, \mathrm{P}$} \\
\hline & SPM (N) & $\%$ & SPM (N) & $\%$ & $\mathrm{OPC}$ & Non-OPC & $\mathrm{OPC}$ & Non-OPC \\
\hline \multicolumn{9}{|c|}{ FAS $670 A>G$} \\
\hline AA (ref.) & 7 & 16.7 & 13 & 15.9 & 1.0 & 1.0 & 1.0 & 1.0 \\
\hline$A G+G G$ & 35 & 83.3 & 69 & 84.1 & $1.9(0.8-4.9), 0.121$ & $2.2(1.2-5.7), 0.048$ & $2.2(0.9-5.3), 0.051$ & $2.4(1.1-5.1), 0.043$ \\
\hline \multicolumn{9}{|c|}{ FAS $1377 \mathrm{G}>A$} \\
\hline GG (ref.) & 34 & 80.9 & 64 & 78.0 & 1.0 & 1.0 & 1.0 & 1.0 \\
\hline$A G+A A$ & 8 & 19.1 & 18 & 22.0 & $0.7(0.3-2.1), 0.435$ & $1.1(0.4-1.6), 0.378$ & $0.8(0.4-1.9), 0.476$ & $1.0(0.5-1.8), 0.622$ \\
\hline \multicolumn{9}{|c|}{ FASL124 A > G } \\
\hline AA (ref.) & 31 & 73.8 & 63 & 76.8 & 1.0 & 1.0 & 1.0 & 1.0 \\
\hline$A G+G G$ & 11 & 26.2 & 19 & 23.2 & $1.0(0.4-2.7), 0.489$ & $1.4(0.7-2.8), 0.567$ & $1.1(0.5-2.4), 0.587$ & $1.6(0.9-3.0), 0.124$ \\
\hline \multicolumn{9}{|c|}{ FASL844 C > T } \\
\hline CC (ref.) & 11 & 26.2 & 26 & 31.7 & 1.0 & 1.0 & 1.0 & 1.0 \\
\hline$C T+\pi$ & 31 & 73.8 & 56 & 68.3 & $2.5(1.1-5.8), 0.043$ & $1.8(1.1-3.2), 0.041$ & $2.7(1.2-6.0), 0.032$ & $1.7(1.0-3.0), 0.049$ \\
\hline
\end{tabular}

ref.: reference group

${ }^{\text {a }}$ Crude HRs

${ }^{\mathrm{b}} \mathrm{HRs}$ were adjusted for age, sex, ethnicity, smoking, alcohol, index cancer stage, and treatment

group based on the number of variant genotypes of the 4 polymorphisms. For the combined analysis, we found that the patients carrying 3 or 4 variant genotypes had an approximately 2 -fold significantly increased risk of SPM compared with those with $0-1$ variant genotypes only for nonOPC in univariate Cox analyses (cHR, 1.8 and 2.7, $95 \% \mathrm{CI}$, $0.9-3.5$ and $1.2-6.1$, and $P=0.061$ and 0.014 , respectively) and multivariable Cox analyses (aHR, 1.8 and 2.2, $95 \% \mathrm{CI}$, $1.0-3.9$ and $1.2-6.5$, and $P=0.051$ and 0.021 , respectively), while such significant associations were not found for OPC patients (Table 3).

\section{Stratification analysis of the combined FAS/FASL genotypes with risk of SPM}

In the stratified analysis by smoking and drinking status, to increase statistical power, we categorized the patients into 2 groups based on the number of combined variant genotypes of the 4 polymorphisms (1) low-risk group (carrying 0-2 variant genotypes) and (2) high-risk group (carrying 3-4 variant genotypes) shown in Table 4. As we expected, the OPC patients in high-risk group had significantly increased risk for SPMs compared with those in low-risk group only for never smokers (cHR; 18.9, $95 \% \mathrm{CI}$; $1.3-330.2$, and $P=0.032$ and aHR; 20.0, $95 \% \mathrm{CI} ; 1.2-327.0$, and $P=0.028$, respectively) but not for ever smokers (cHR; 1.4, $95 \% \mathrm{CI}$; $0.5-3.3$, and $P=0.722$ and aHR; $1.4,95 \%$ CI; $0.6-3.4$, and $P=0.787$, respectively). No such significant associations were found for either ever drinkers or never drinkers among index OPC patients (Table 4). However, the non-OPC patients in high-risk group had an approximately 2-fold significantly increased risk of SPM compared with those in low-risk group in both ever smokers (cHR; 2.1, $95 \%$ CI; $1.1-4.2, P=0.013$ and aHR; 2.3, $95 \% \mathrm{CI}$; 1.2-4.4, and $P=0.011$, respectively) and ever drinkers (cHR; 2.3, $95 \% \mathrm{CI} ; 1.1-3.9$, and $P=0.022$ and aHR; 2.2 , $95 \% \mathrm{CI}$; $1.2-4.1$, and $P=0.019$, respectively), whereas such significant associations were not observed in either never smokers (cHR; 0.2, $95 \% \mathrm{CI}$; 0.1-1.4, and $P=0.346$ and aHR; $0.1,95 \%$ CI; $0.0-1.2$, and $P=0.323$, respectively) or never drinkers (cHR; $0.5,95 \% \mathrm{CI} ; 0.2-4.3$, and $P=0.798$ and aHR; $0.6,95 \% \mathrm{CI}$; 0.1-4.1, and $P=0.801$, respectively).

Table 3 SPM risk associated with combined FAS/FASL variant genotypes after index OPC and non-OPC

\begin{tabular}{|c|c|c|c|c|c|c|}
\hline \multirow{2}{*}{$\begin{array}{l}\text { No. variant } \\
\text { genotypes }\end{array}$} & \multirow{2}{*}{$\begin{array}{l}\text { OPC } \\
\text { SPM/SPM-free } \\
(42 / 710)\end{array}$} & \multirow{2}{*}{$\begin{array}{l}\text { Non-OPC } \\
\text { SPM/SPM-free } \\
(n=82 / 695)\end{array}$} & \multicolumn{2}{|l|}{$\mathrm{CHRs}^{\mathrm{a}}(95 \% \mathrm{Cl}), \mathrm{P}$} & \multicolumn{2}{|l|}{ aHRs $(95 \% \mathrm{Cl})^{\mathrm{b}}, \mathrm{P}$} \\
\hline & & & OPC & Non-OPC & $\mathrm{OPC}$ & Non-OPC \\
\hline 0-1 (ref.) & $5 / 142$ & $10 / 132$ & 1.0 & 1.0 & 1.0 & 1.0 \\
\hline 2 & $15 / 256$ & $27 / 264$ & $1.3(0.4-3.5), 0.673$ & $1.4(0.6-2.7), 0.585$ & $1.3(0.5-3.7), 0.698$ & $1.5(0.5-3.3), 0.612$ \\
\hline 3 & $16 / 220$ & $31 / 229$ & $1.6(0.6-4.1), 0.587$ & $1.8(0.9-3.5), 0.061$ & $1.7(0.5-3.8), 0.632$ & $1.8(1.0-3.9), 0.051$ \\
\hline 4 & $6 / 92$ & $14 / 70$ & $2.2(0.9-6.8), 0.112$ & $2.7(1.2-6.1), 0.014$ & $2.0(0.9-6.6), 0.110$ & $2.2(1.2-6.5), 0.021$ \\
\hline
\end{tabular}

${ }^{\text {a Crude HRs }}$

${ }^{\mathrm{b}} \mathrm{HRs}$ were adjusted for age, sex, ethnicity, smoking, alcohol, index cancer stage, and treatment 
Table 4 SPM risk associated with combined FAS/FASL variant genotypes after index OPC and non-OPC, stratified by smoking and alcohol

\begin{tabular}{|c|c|c|c|c|c|c|}
\hline \multirow[t]{2}{*}{ Variables } & \multicolumn{2}{|c|}{ Low-risk group ${ }^{a}$} & \multicolumn{2}{|c|}{ High-risk group ${ }^{b}$} & \multirow{2}{*}{$\begin{array}{l}\text { CHRs }^{c},(95 \% \mathrm{Cl}), \mathrm{P} \\
\text { Low-risk group (ref.) vs. High-risk group }\end{array}$} & \multirow{2}{*}{$\begin{array}{l}\text { aHRs }^{d} \text { (95 \% Cl), P } \\
\text { Low-risk group (ref.) vs. High-risk group }\end{array}$} \\
\hline & No. & $\%$ & No. & $\%$ & & \\
\hline OPC & 575 & 76.5 & 177 & 23.5 & & \\
\hline \multicolumn{7}{|c|}{ Smoking } \\
\hline Ever & 325 & 56.5 & 104 & 58.8 & $1.4(0.5-3.3), 0.722$ & $1.4(0.6-3.4), 0.787$ \\
\hline Never & 250 & 43.5 & 73 & 41.2 & $18.9(1.3-330.2), 0.032$ & $20.0(1.2-327.0), 0.028$ \\
\hline \multicolumn{7}{|l|}{ Alcohol } \\
\hline Ever & 421 & 73.2 & 128 & 72.3 & $1.3(0.3-3.7), 0.823$ & $1.4(0.5-3.8), 0.822$ \\
\hline Never & 154 & 26.8 & 49 & 27.7 & $1.9(0.3-17.2), 0.887$ & $1.8(0.2-16.1), 0.867$ \\
\hline Non-OPC & 614 & 79.0 & 163 & 21.0 & & \\
\hline \multicolumn{7}{|l|}{ Smoking } \\
\hline Ever & 455 & 74.1 & 125 & 76.7 & $2.1(1.1-4.2), 0.013$ & $2.3(1.2-4.4), 0.011$ \\
\hline Never & 159 & 25.9 & 38 & 23.3 & $0.2(0.1-1.4), 0.346$ & $0.1(0.0-1.2), 0.323$ \\
\hline \multicolumn{7}{|l|}{ Alcohol } \\
\hline Ever & 426 & 69.4 & 124 & 76.1 & $2.3(1.1-3.9), 0.022$ & $2.2(1.2-4.1), 0.019$ \\
\hline Never & 188 & 30.6 & 39 & 23.9 & $0.5(0.2-4.3), 0.798$ & $0.6(0.1-4.1), 0.801$ \\
\hline
\end{tabular}

aLow-risk group: 0-2 variant genotypes

bHigh-risk group: 3-4 variant genotypes

${ }^{c}$ Crude HRs

${ }^{\mathrm{d}}$ HRs were adjusted for age, sex, ethnicity, smoking, alcohol, index cancer stage, and treatment

\section{Discussion}

In the present study, we evaluated the associations between the functional FAS/FASL polymorphisms and the risk of SPMs among both index OPC versus index nonOPC patients. We found that these polymorphisms modified the risk of SPMs differently for index OPC from non-OPC patients. Furthermore, when we stratified the risk factors of smoking and drinking status for further analysis, the significant associations of $F A S / F A S L$ variant genotypes with the risk of SPM were observed within several subgroups. These results might suggest that genetic factors, within the context of previous or continued exposure to smoking and alcohol may affect the risk of SPM after index OPC and non-OPC patients. These results support growing evidence showing that apoptosis is associated with risk of SPMs; and tumor site factor may contribute to this association. Thus, apoptotic variants modify the risk of SPMs associated with the smoking and alcohol exposure in a tumor sitespecific manner.

The roles of FAS and FASL in tumor formation have been well studied. The down-regulation of FAS may protect tumor cells from elimination by antitumor immune responses, whereas up-regulation of FASL may increase the ability of tumor cells to counterattack the immune system by inducing apoptosis of FAS-sensitive lymphocytes [30-33]. Therefore, alteration of the FAS and FASL expressions may decrease the apoptotic ability of cells, and many tumor cells may evade or suppress the immune system. Most of the studies suggested that decreased FAS gene expression and/or increased FASL gene expression is a common feature of malignant transformation and an early event associated with the development of human cancers [26, 34-42]. Survival analyses have shown that FAS1377 and FAS670 polymorphisms are associated with lower survival in early stage nonsmall cell lung cancer patients and increased risk of recurrence and death in epithelial ovarian cancer patients $[38,43]$. These findings support the biological plausibility that the alteration of $F A S$ or $F A S L$ genes, such as functional genetic polymorphisms, may affect the risk for tumor development, including SPM.

These four polymorphisms in gene promoters may affect function of $F A S$ and $F A S L$ genes, and result in expression changes of these genes [26, 27, 42]. Change of FAS or FASL expression resulting from their promoter variants may help the transformed cells evade FASmediated cell death, subsequently affecting risk for SPMs. In the current study, we observed a significant association between FAS670 polymorphism with risk for developing SPMs among index non-OPC but not for OPC patients, while a significant association of FASL844 polymorphism with risk of SPMs among both index OPC and non-OPC patients. These findings might suggest that there were different etiologies between OPC and non-OPC patients underlying these observed associations. Although these polymorphisms are considered to be biologically functional, the findings on the association between risk of 
SPMs and these putatively functional polymorphisms were inconsistent. It might be likely that the study patients were stratified by the index tumor sites, which is a potential confounding factor when studying overall index SCCHN patients.

Previous studies suggested that the two FAS or FASL polymorphisms were not in a linkage disequilibrium and these polymorphisms had a joint effect on cancer risk [26], and the combined FAS/FASL genotypes were associated with a significantly increased risk of SCCHN. In the current study, such a significant association of the combined variant genotypes of these polymorphisms with the risk of SPM was found for non-OPC but not for OPC. The presence and absence of the joint effect among index OPC patients and index non-OPC might result from the different roles of FAS/FASL polymorphisms in etiology of SPM development through gene-gene or gene-environment (smoking, alcohol, HPV status, and other environmental risk factors) interactions in different site of SCCHN tissues.

Tobacco smoking, alcohol use, and HPV infection have been well-established as risk factors for SCCHN, particularly smoking/alcohol for non-OPC, and HPV for OPC. Several studies have reported such gene-environmental interactions on risk of SCCHN. A study on Taiwanese population reported that $F A S 1377$ and $F A S 670$ polymorphisms were strongly correlated with environmental factors like cigarette smoking, betel chewing, and alcohol drinking and had effects on increased risk of oral cancers [44]. Another study on Asian Indian population also found FAS1377, FAS670, and FASL844 polymorphisms interacted with tobacco smoking to increase the risk of oral cancers [45-47]. The interaction effect between smoking and FASL844 polymorphism on the risk was also observed in other types of cancer, including lung, pancreatic, and esophageal cancers [34, 36, 48, 49]. Our current study when stratified by smoking and alcohol status showed a consistency with the previous studies. The patients with index non-OPC, who had the combined variant genotypes and who were ever smokers and ever drinkers, had a significantly higher risk for SPMs, while the patients with OPC, who had the combined variant genotypes and who were never smokers, had a significantly higher risk for SPMs, but no such a significant risk was found among ever smokers. This might be because that index non-OPC are caused by smoking and alcohol exposure, whereas most of index OPC patients occurs in never smokers and are caused by HPV.

This is the first study to evaluate the associations between FAS/FASL polymorphisms and the risk for SPM among index OPC versus non-OPC patients. Although previous studies have found significant associations between the polymorphisms and SPM among the SCCHN patients, they did not consider index tumor site as an important confounding factor for such association due to different risk factors for OPC from non-OPC patients. Since OPC has distinguished epidemiological and clinical features along with prognosis that are different from non-OPC, it is important to investigate the associations stratified by the tumor sites. Therefore, this current study might provide novel information with clinician for secondary cancer prevention and improved prognosis of patients with primary SCCHN.

The results from such a stratified analysis by index tumor site in the present study is essential to improving long-term patient outcomes and accurate understanding the unique risk factors and carcinogenesis of SCCHN at particular subsites. In addition, the high frequency of SPM occurs in approximately $15 \%$ of SCCHN patients. In patients with SCCHN, index cancer site, HPV status, and smoking use greatly affect the risk and distribution of SPM. Although the incidence of SCCHN in the U.S. has been in decline over past two decades and the diagnostic and therapeutic approaches for the patients have been improved, the poor prognosis for OPC and non-OPC patients has moderately and not significantly improved, respectively. Therefore, FAS and FASLG polymorphisms may serve as a marker for genetic susceptibility to SPMs after index HPV-associated OPC and non-HPV-associated non-OPC, and for identifying high-risk subgroups in each cohort who might benefit from management of alternative treatment and predictable patient outcome. Moreover, identifying markers of risk for SPM among cancer survivors is currently limited to rather simplistic clinical posttreatment screenings.

There are several limitations in the current study. Firstly, a selection bias likely exists for study patients due to the hospital-based nature of this study. Secondly, as the rate of SPM is low in the index patient populations, the numbers of SPM event are limited the statistical power in this study. After series of stratifications, the numbers in some of the stratum or subgroups are relatively small, thus our results may come by chance. Thirdly, the late stage patients may have limited time for follow-up, since those patients might not have enough time to develop SPMs. Thus, the limited follow-up time may bias our estimates of the associations. Furthermore, screening bias in detecting SPM's is not fully ruled out, since tobacco-associated SPMs are usually easier to be detected than non-tobacco-associated SPM. And finally, due to the retrospective nature of the original study design, we did not have enough information on HPV infection and the continued smoking behavior after index patient diagnosis, and these potential confounders could also bias the observed associations.

\section{Conclusion}

FAS/FASL variants may individually or jointly modify the risk of SPM in OPC and non-OPC differently, particularly 
in some subgroups. Further studies with larger sample size are warranted to validate our findings; and these large molecular epidemiological association studies also should be considered to incorporate HPV information and smoking behavior after index cancer diagnosis or treatment into the study design.

\section{Abbreviations}

SCCHN: squamous cell carcinoma of the head and neck; SPM: second primary malignancies; HR: hazard ratio; 95 \% Cl: 95 \% confidence interval; HPV: human papillomavirus; OPC: oropharyngeal cancer; non-OPC: nonoropharyngeal cancer.

\section{Competing interests}

The authors declare that they have no competing interests.

\section{Authors' contributions}

YS, WY, and WP participated in the design of the study and carried out all the experiments and wrote the initial drafts of manuscript. EMS, DL and QW participated in study design and manuscript preparation. WP participated in data analysis and statistical analysis. XS, WY and GL participated in study design data analysis, manuscript writing, and revision. All authors read and approved the final manuscript.

\section{Acknowledgements}

We thank Margaret Lung, Liliana Mugartegui with assistance with patient recruitment and Ms. Yingdong Li for their help in laboratory.

\section{Funded by}

U.T. M.D. Anderson Cancer Center Start-up Funds (to E.M.S.) and National Institute of Health Grants R01 ES-11740 and CA-131274 (to Q.W.); and N.I.H. CA135679 (to G.L.) and CA133099 (to G.L.).

\section{Author details}

'Department of Head and Neck Surgery, Unit 1445, The University of Texas MD Anderson Cancer Center, 1515 Holcombe Boulevard, Houston TX 77030, USA. ${ }^{2}$ Department of Otorhinolaryngology and Head and Neck Surgery, Yuhuangding Hospital of Qingdao University, Yantai, China. ${ }^{3}$ Key Laboratory of Carcinogenesis and Translational Research(Ministry of Education/Beijing), Department of Head and Neck surgery, Peking University Cancer Hospital \& Institute, Beijing, China. ${ }^{4}$ Department of Epidemiology, The University of Texas MD Anderson Cancer Center, Houston TX 77030, USA. ${ }^{5}$ Department of Biostatistics and Human Genetics Center, University of Texas School of Public Health, 1200 Herman Pressler St, Houston TX 77030, USA. ${ }^{6}$ Department of Otolaryngology, Qilu Hospital, Shandong University; Key Laboratory of Otolaryngology, Ministry of Health, P.R. China, Jinan, Shandong 250012, China. 'Duke Cancer Institute, Duke University Medical Center, Durham, NC 27710, USA.

\section{Received: 28 August 2015 Accepted: 3 February 2016} Published online: 08 February 2016

\section{References}

1. Li G, Sturgis EM. The role of human papillomavirus in squamous carcinoma of the head and neck. Curr Oncol Rep. 2006;8(2):130-9.

2. Sturgis EM, Miller RH. Second primary malignancies in the head and neck cancer patient. Ann Otol Rhinol Laryngol. 1995;104(12):946-54.

3. Morris LG, Sikora AG, Patel SG, Hayes RB, Ganly I. Second primary cancers after an index head and neck cancer: subsite-specific trends in the era of human papillomavirus-associated oropharyngeal cancer. Journal of Clin Oncol. 2011;29(6):739-46. doi:10.1200/JCO.2010.31.8311.

4. Bosetti C, Scelo G, Chuang SC, Tonita JM, Tamaro S, Jonasson JG, et al. High constant incidence rates of second primary cancers of the head and neck: a pooled analysis of 13 cancer registries. Int J Cancer. 2011;129(1):173-9. doi: 10.1002/ijc.25652.

5. Leon X, Quer M, Diez S, Orus C, Lopez-Pousa A, Burgues J. Second neoplasm in patients with head and neck cancer. Head Neck. 1999; 21(3):204-10.

6. Vokes EE, Weichselbaum RR, Lippman SM, Hong WK. Head and neck cancer. N Engl J Med. 1993;328(3):184-94. doi:10.1056/NEJM199301213280306.
7. Ernster JA, Sciotto CG, O'Brien MM, Finch JL, Robinson $L$, Willson T, et al. Rising incidence of oropharyngeal cancer and the role of oncogenic human papilloma virus. Laryngoscope. 2007;1 17(12):2115-28. doi:10.1097/MLG.0b01 3e31813e5fbb.

8. Nasman A, Attner P, Hammarstedt L, Du J, Eriksson M, Giraud G, et al. Incidence of human papillomavirus (HPV) positive tonsillar carcinoma in Stockholm, Sweden: an epidemic of viral-induced carcinoma? Int J Cancer. 2009;125(2):362-6. doi:10.1002/ijc.24339.

9. Maxwell JH, Kumar B, Feng FY, Worden FP, Lee JS, Eisbruch A, et al. Tobacco use in human papillomavirus-positive advanced oropharynx cancer patients related to increased risk of distant metastases and tumor recurrence. Clin Cancer Res. 2010;16(4):1226-35. doi:10.1158/1078-0432.CCR-09-2350.

10. Rennemo E, Zatterstrom U, Boysen M. Impact of second primary tumors on survival in head and neck cancer: an analysis of 2,063 cases. Laryngoscope. 2008;118(8):1350-6. doi:10.1097/MLG.0b013e318172ef9a.

11. Yamamoto E, Shibuya H, Yoshimura R, Miura M. Site specific dependency of second primary cancer in early stage head and neck squamous cell carcinoma. Cancer. 2002;94(7):2007-14.

12. Zhang Y, Sturgis EM, Zafereo ME, Wei Q, Li G. p14ARF genetic polymorphisms and susceptibility to second primary malignancy in patients with index squamous cell carcinoma of the head and neck. Cancer. 2011;117(6):1227-35. doi:10.1002/cncr.25605

13. Day GL, Blot WJ, Shore RE, McLaughlin JK, Austin DF, Greenberg RS, et al. Second cancers following oral and pharyngeal cancers: role of tobacco and alcohol. J Natl Cancer Inst. 1994;86(2):131-7.

14. Do KA, Johnson MM, Lee JJ, Wu XF, Dong Q, Hong WK, et al. Longitudinal study of smoking patterns in relation to the development of smokingrelated secondary primary tumors in patients with upper aerodigestive tract malignancies. Cancer. 2004;101(12):2837-42. doi:10.1002/cncr.20714.

15. Wu X, Spitz MR, Lee JJ, Lippman SM, Ye Y, Yang H, et al. Novel susceptibility loci for second primary tumors/recurrence in head and neck cancer patients: large-scale evaluation of genetic variants. Cancer Prevention Res. 2009;2(7):617-24. doi:10.1158/1940-6207.CAPR-09-0025.

16. Gal TJ, Huang WY, Chen C, Hayes RB, Schwartz SM. DNA repair gene polymorphisms and risk of second primary neoplasms and mortality in oral cancer patients. Laryngoscope. 2005;115(12):2221-31. doi:10.1097/01. mlg.0000183736.96004.f7.

17. Minard CG, Spitz MR, Wu X, Hong WK, Etzel CJ. Evaluation of glutathione $S$-transferase polymorphisms and mutagen sensitivity as risk factors for the development of second primary tumors in patients previously diagnosed with early-stage head and neck cancer. Cancer. 2006;106(12):2636-44. doi:10.1002/cncr.21928.

18. Li F, Sturgis EM, Zafereo ME, Liu Z, Wang LE, Wei Q, et al. p73 G4C14-toA4T14 polymorphism and risk of second primary malignancy after index squamous cell carcinoma of head and neck. Int J Cancer. 2009;125(11):2660-5. do:10.1002/ijc.24570.

19. Zafereo ME, Sturgis EM, Aleem S, Chaung K, Wei Q, Li G. Glutathione S-transferase polymorphisms and risk of second primary malignancy after index squamous cell carcinoma of the head and neck. Cancer Prevention Res. 2009;2(5):432-9. doi:10.1158/1940-6207.CAPR-08-0222.

20. Zafereo ME, Sturgis EM, Liu Z, Wang LE, Wei Q, Li G. Nucleotide excision repair core gene polymorphisms and risk of second primary malignancy in patients with index squamous cell carcinoma of the head and neck. Carcinogenesis. 2009;30(6):997-1002. doi:10.1093/carcin/bgp096.

21. Lei D, Sturgis EM, Liu Z, Zafereo ME, Wei Q, Li G. Genetic polymorphisms of p21 and risk of second primary malignancy in patients with index squamous cell carcinoma of the head and neck. Carcinogenesis. 2010;31(2):222-7. doi:10.1093/carcin/bgp279.

22. Zornig M, Hueber A, Baum W, Evan G. Apoptosis regulators and their role in tumorigenesis. Biochim Biophys Acta. 2001;1551(2):F1-37.

23. Thompson CB. Apoptosis in the pathogenesis and treatment of disease Science. 1995;267(5203):1456-62.

24. Evan GI, Vousden KH. Proliferation, cell cycle and apoptosis in cancer. Nature. 2001;411(6835):342-8. doi:10.1038/35077213.

25. Itoh N, Yonehara S, Ishii A, Yonehara M, Mizushima S, Sameshima M, et al. The polypeptide encoded by the CDNA for human cell surface antigen Fas can mediate apoptosis. Cell. 1991;66(2):233-43.

26. Zhang Z, Wang LE, Sturgis EM, El-Naggar AK, Hong WK, Amos Cl, et al. Polymorphisms of FAS and FAS ligand genes involved in the death pathway and risk and progression of squamous cell carcinoma of the head and neck. Clin Cancer Res. 2006;12(18):5596-602. doi:10.1158/1078-0432.CCR-05-1739. 
27. Takahashi T, Tanaka M, Inazawa J, Abe T, Suda T, Nagata S. Human Fas ligand: gene structure, chromosomal location and species specificity. Int Immunol. 1994;6(10):1567-74.

28. Lei D, Sturgis EM, Wang LE, Liu Z, Zafereo ME, Wei Q, et al. FAS and FASLG genetic variants and risk for second primary malignancy in patients with squamous cell carcinoma of the head and neck. Cancer Epidemiol Biomarkers Prevention. 2010;19(6):1484-91. doi:10.1158/1055-9965.EPI-10-0030.

29. Warren S, Gates O. Multiple primary malignant tumors a survey of the literature and a statistical study. Am J Cancer. 1932;16:1358-414.

30. Reichmann E. The biological role of the Fas/FasL system during tumor formation and progression. Semin Cancer Biol. 2002;12(4):309-15.

31. Griffith TS, Brunner T, Fletcher SM, Green DR, Ferguson TA. Fas ligandinduced apoptosis as a mechanism of immune privilege. Science. 1995;270(5239):1189-92.

32. Strand S, Hofmann WJ, Hug H, Muller M, Otto G, Strand D, et al. Lymphocyte apoptosis induced by CD95 (APO-1/Fas) ligand-expressing tumor cells-a mechanism of immune evasion? Nat Med. 1996;2(12):1361-6.

33. Muschen M, Warskulat U, Beckmann MW. Defining CD95 as a tumor suppressor gene. J Mol Med. 2000;78(6):312-25.

34. Zhang X, Miao X, Sun T, Tan W, Qu S, Xiong P, et al. Functional polymorphisms in cell death pathway genes FAS and FASL contribute to risk of lung cancer. J Med Genet. 2005;42(6):479-84. doi:10.1136/jmg.2004.030106.

35. Zhang B, Sun T, Xue L, Han X, Zhang B, Lu N, et al. Functional polymorphisms in FAS and FASL contribute to increased apoptosis of tumor infiltration lymphocytes and risk of breast cancer. Carcinogenesis. 2007;28(5):1067-73. doi:10.1093/carcin/bgl250.

36. Sun T, Miao X, Zhang X, Tan W, Xiong P, Lin D. Polymorphisms of death pathway genes FAS and FASL in esophageal squamous-cell carcinoma. J Natl Cancer Inst. 2004;96(13):1030-6.

37. Yang S, Miao XP, Zhang XM, Sun T, Qu SN, Xiong P, et al. Genetic polymorphisms of apoptosis-associated genes FAS and FASL and risk of colorectal cancer. Zhonghua yi xue za zhi. 2005;85(30):2132-5.

38. Ueda M, Terai Y, Kanda K, Kanemura M, Takehara M, Yamaguchi H, et al. Fas gene promoter -670 polymorphism in gynecological cancer. International J Gynecol Cancer. 2006;16 Suppl 1:179-82. doi:10.1111/j.1525-1438.2006. 00505.X.

39. Li Y, Hao YL, Kang S, Zhou RM, Wang N, Qi BL. Genetic polymorphisms in the Fas and FasL genes are associated with epithelial ovarian cancer risk and clinical outcomes. Gynecol Oncol. 2013;128(3):584-9. doi:10.1016/j.ygy no.2012.12.002.

40. Lai HC, Lin WY, Lin YW, Chang CC, Yu MH, Chen CC, et al. Genetic polymorphisms of FAS and FASL (CD95/CD95L) genes in cervical carcinogenesis: An analysis of haplotype and gene-gene interaction. Gynecol Oncol. 2005;99(1):113-8. doi:10.1016/j.ygyno.2005.05.010.

41. Krippl P, Langsenlehner U, Renner W, Koppel H, Samonigg H. Re: Polymorphisms of death pathway genes FAS and FASL in esophageal squamous-cell carcinoma. J Natl Cancer Inst. 2004;96(19):1478-9. doi:10.1093/jnci/djh289. author reply 9.

42. Sun T, Zhou Y, Li H, Han X, Shi Y, Wang L, et al. FASL -844C polymorphism is associated with increased activation-induced T cell death and risk of cervical cancer. J Exp Med. 2005;202(7):967-74. doi:10.1084/jem.20050707.

43. Park JY, Lee WK, Jung DK, Choi JE, Park TI, Lee EB, et al. Polymorphisms in the FAS and FASL genes and survival of early stage non-small cell lung cancer. Clin Cancer Res. 2009;15(5):1794-800. doi:10.1158/1078-0432.CCR08-1770.

44. Wang LH, Ting SC, Chen CH, Tsai CC, Lung O, Liu TC, et al. Polymorphisms in the apoptosis-associated genes FAS and FASL and risk of oral cancer and malignant potential of oral premalignant lesions in a Taiwanese population. J Oral Pathology Med. 2010;39(2):155-61. doi:10.1111/j.16000714.2009.00873.X.

45. Cao Y, Miao XP, Huang MY, Deng L, Lin DX, Zeng YX, et al. Polymorphisms of death pathway genes FAS and FASL and risk of nasopharyngeal carcinoma. Mol Carcinog. 2010;49(11):944-50. doi:10.1002/mc.20676.

46. Karimi MY, Kapoor V, Sharma SC, Das SN. Genetic polymorphisms in FAS (CD95) and FAS ligand (CD178) promoters and risk of tobacco-related oral carcinoma: gene-gene interactions in high-risk Indians. Cancer Invest. 2013;31(1):1-6. doi:10.3109/07357907.2012.743555.

47. Wang J, Gao J, Li Y, Zhao X, Gao W, Peng L, et al. Functional polymorphisms in FAS and FASL contribute to risk of squamous cell carcinoma of the larynx and hypopharynx in a Chinese population. Gene. 2013;524(2):193-6. doi:10.1016/j.gene.2013.04.034.
48. Souza RF, Shewmake K, Pearson S, Sarosi Jr GA, Feagins LA, Ramirez RD, et al. Acid increases proliferation via ERK and p38 MAPK-mediated increases in cyclooxygenase-2 in Barrett's adenocarcinoma cells. Am J Physiol Gastrointest Liver Physiol. 2004;287(4):G743-8. doi:10.1152/ajpgi.00144.2004.

49. Yang M, Sun T, Wang L, Yu D, Zhang X, Miao X, et al. Functional variants in cell death pathway genes and risk of pancreatic cancer. Clin Cancer Res. 2008;14(10):3230-6. doi:10.1158/1078-0432.CCR-08-0177.

\section{Submit your next manuscript to BioMed Central and we will help you at every step:}

- We accept pre-submission inquiries

- Our selector tool helps you to find the most relevant journal

- We provide round the clock customer support

- Convenient online submission

- Thorough peer review

- Inclusion in PubMed and all major indexing services

- Maximum visibility for your research

Submit your manuscript at www.biomedcentral.com/submit
C Biomed Central 